\title{
Effect of Chitosan on the Rheological and Sensorial Characteristics of Apulia Spreadable Cheese
}

\author{
D. Gammariello, ${ }^{*}$ S. Chillo, ${ }^{*}$ M. Mastromatteo,† S. Di Giulio, $\ddagger$ M. Attanasio, ${ }^{*}$ and M. A. Del Nobile ${ }^{*} \ddagger^{1}$ \\ *Istituto per la Ricerca e le Applicazioni Biotecnologiche per la Sicurezza e la Valorizzazione dei Prodotti Tipici e di Qualità, \\ †Department of Production Science, Engineering, Mechanics, Economics in Agriculture and Livestock Systems, and \\ ‡Department of Food Science, University of Foggia, via Napoli, 25-71100 Foggia, Italy
}

\section{ABSTRACT}

The effect of chitosan on the rheological and sensorial properties of Apulia spreadable cheese during storage time was evaluated. The investigated spreadable cheese samples were stored at $4^{\circ} \mathrm{C}$. Storage modulus $\left(\mathrm{G}^{\prime}\right)$, loss modulus $\left(\mathrm{G}^{\prime \prime}\right)$, $\tan \delta$, and the overall sensorial quality of the spreadable cheese were monitored for $24 \mathrm{~d}$. Moreover, moisture content, $\mathrm{pH}$, color, and lactic acid bacteria during storage time were evaluated. Results indicate that statistically significant differences in $\mathrm{G}^{\prime}, \mathrm{G}^{\prime \prime}$, and $\tan \delta$ values and in the sensorial scores exist between the control sample and the spreadable cheese samples with chitosan. In particular, chitosan improved the rheological and sensorial properties of the spreadable cheese, particularly its softness. Moreover, its addition influenced the physicochemical properties of the investigated spreadable cheese during storage time, without affecting the dairy microflora.

Key words: spreadable cheese, chitosan, rheological property, sensorial characteristic

\section{INTRODUCTION}

Obtained from raw or pasteurized milk, spreadable cheeses are characterized by a soft, creamy paste, an elastic texture, and rapid ripening due to the high percentage of water. They are white and homogeneous in color, with a delicate smell. Spreadable cheeses are widely used, especially in Europe, where their mild taste, velvety texture, and versatility (Lante et al., 2006) are prized. During the manufacture of spreadable cheese, some water is added to produce a smooth and stable emulsion (Berger et al., 1993). Water helps to dissolve the calcium chelating salts by hydrating the proteins and dispersing the components. Water is also required to achieve certain product attributes such as

Received April 18, 2008.

Accepted June 17, 2008.

${ }^{1}$ Corresponding author: ma.delnobile@unifg.it softness or meltability in processed cheese slices (Lee et al., 2004). All soft cheeses have a moisture content from 40 to $60 \%$. A drawback of cheese with a high moisture content is its susceptibility to spoilage. Moisture variation can also affect the rheological properties, shelf life (Lee et al., 2004), and sensorial characteristics.

In the literature, several studies focus on the rheological properties of natural and processed cheeses (Zalazar et al., 2002; Piska and Štětina, 2004; San Martín-González et al., 2007; Dimitreli and Thomareis, 2008). Others have been carried out on the relationship between the rheological and sensorial properties of cheese (Sipahioglu et al., 1999; Romeih et al., 2002; Koca and Metin, 2004; Konuklar et al., 2004). To improve the textural and sensorial properties of low-fat cheese, various substances have been used in cheesemaking, including cereals, whey and milk proteins, various carbohydrates such as B-glucan, and modified starches (Drake et al., 1996; McMahon et al., 1996; Ma et al., 1997). Moreover, Dickinson (1998) carried out studies on the stability and rheological implications of the interaction of several polysaccharides, in particular carrageenans and pectins with milk components.

Chitosan is a modified, natural polysaccharide made up of copolymers of glucosamine and $\mathrm{N}$-acetylglucosamine, and it derives from alkaline deacetylation of chitin obtained from the exoskeletons of crustaceans and arthropods (Li et al., 1997). The addition of chitosan to whole or skimmed milk produces destabilization, resulting in the formation of chitosan-casein-fat coagula. These aggregates are hydrolyzed by digestive proteases. However, the presence of chitosan inhibited the hydrolysis of triglycerides through the action of pancreatic lipase. The consequence of this phenomenon is that almost half of triglycerides remain associated with the aggregates in a nonabsorbable form (Ausar et al., 2001a,b, 2002). In addition, chitosan has attracted considerable attention because of its notable biological activities (Sekiguchi et al., 1994), such as antimicrobial (Altieri et al., 2005), antitumoral (Tokoro et al., 1988), and hypocholesterolemic functions (Sugano et al., 1992; No et al., 2007). 
Evaluating the potential use of chitosan in the manufacture of dairy products, the possibility of the addition of chitosan in Apulia spreadable cheese was investigated. The aim of this work was to study the effect of chitosan on the rheological and sensorial characteristics, as well as on the moisture content, $\mathrm{pH}$, color, and lactic acid bacteria evaluation of the Apulia spreadable cheese during the storage period.

\section{MATERIALS AND METHODS}

\section{Cheese Making}

Spreadable cheese samples were manufactured in the cheese-making factory "Posta la via" (Foggia, Italy). Four batches, each containing $10 \mathrm{~kg}$ of cow's milk, were prepared and pasteurized at $70^{\circ} \mathrm{C}$ for $2 \mathrm{~min}$. A commercial starter culture $(0.5 \%$, Streptococcus thermophilus strain CR57, Chemifer, Livraga, Lodi, Italy) was revitalized using part of the cow's milk for $45 \mathrm{~min}$ at $37^{\circ} \mathrm{C}$ to improve the growth and activity of lactic bacteria. When the $\mathrm{pH}$ of the revitalized milk reached approximately 5.50, the latter was divided into 4 parts, of which one was used for the control cheese sample. Low-molecular-weight chitosan $(85 \%$ deacetylation; Aldrich, Milan, Italy) was added to the remaining 3 parts to obtain the modified starters. Afterwards, they were put into the working milk to obtain final concentrations of $0.012,0.024$, and $0.036 \%$ (wt/vol) chitosan. For each batch of working milk, $5 \%$ animal liquid rennet (strength 1:10,000) and 1\% sodium chloride were directly added. Coagulation was carried out for about $15 \mathrm{~min}$. The obtained curd was cut longitudinally and transversally into small parts about 10 to $15 \mathrm{~mm}$ in diameter. At the end of this process, the curd was left for $40 \mathrm{~min}$ and then transferred to the mold. In this step, the curd was separated from the whey and put into square molds with holes to allow the draining of the liquid. Finally, the cheese was sweated at 28 to $30^{\circ} \mathrm{C}$. After that, the spreadable cheese samples were put into the refrigerator at 4 to $5^{\circ} \mathrm{C}$. The samples had a ripening period of $7 \mathrm{~d}$. Moreover, according to the producer, they had a shelf life of about $18 \mathrm{~d}$. The 3 spreadable cheeses with the chitosan, named C12 (0.012\%), C24 (0.024\%), and C36 (0.036\%) respectively, were compared with the chitosan-free cheese sample (control). The tests were carried out at different storage times: during the ripening period (i.e., $\mathrm{d} 0,3$, and $\mathrm{d} 7$ ), and during the storage period (i.e., at d 10, 14, 18, 21, and 24).

\section{Chemical and Physicochemical Analyses}

The moisture (\%) of the spreadable cheese samples was determined by dehydration at $105^{\circ} \mathrm{C}$ by using a drying oven (9000 series-RS232, Isco, Milan, Italy). The moisture and $\mathrm{pH}$ were determined in duplicate for each cheese sample. The colorimetric parameter "hue" was determined by using a colorimeter (CR-310, Minolta, Tokyo, Japan) as the average of the 3 replicates.

\section{Rheological Measurement}

Dynamic-mechanical properties of the Apulia spreadable cheese samples were studied using a controlled-strain rotational rheometer (ARES model, TA Instruments, New Castle, DE) equipped with a force rebalance transducer (model 1K-FRTN1, 1-1000g cm, $200 \mathrm{rad} / \mathrm{sec}, 2-2000 \mathrm{gmf}$ ) and parallel plates (superior plate diameter of $25 \mathrm{~mm}$ ). A steady temperature was ensured with an accuracy of $\pm 0.1^{\circ} \mathrm{C}$ by means of a controlled fluid bath unit and an external thermostatic bath. To prevent water evaporation, a suitable cover tool sealing the top of the superior plate was used during testing. Storage modulus $\left(\mathbf{G}^{\prime}\right)$, loss modulus $\left(\mathbf{G}^{\prime \prime}\right)$, and $\tan \delta$ were determined in a frequency range of 0.05 to $10 \mathrm{~Hz}$. The strain value was obtained by preliminary strain sweep oscillatory trials to determine the linear viscoelastic region. The strain sweep oscillatory tests were carried out at a frequency of $1 \mathrm{~Hz}$ and in a range of shear strain of 0.01 to $300 \%$. All experiments were carried out at $4^{\circ} \mathrm{C}$. Three repetitions of the dynamic mechanical experiments were performed for each spreadable cheese sample. To compare the $\mathrm{G}^{\prime}, \mathrm{G}^{\prime \prime}$, and $\tan \delta$ values between the investigated spreadable cheese samples an oscillatory frequency of $10 \mathrm{~Hz}$ was chosen as a reference (Dimitreli and Thomareis, 2008).

\section{Microbiological Analysis}

Ten grams of each spreadable cheese sample was homogenized in $90 \mathrm{~mL}$ of saline solution $(0.9 \% \mathrm{NaCl})$. Afterwards, serial 10-fold dilutions were prepared and counts of lactic acid bacteria enumerated using the pour-plate technique (APHA, 2001). Lactic acid bacilli grew on de Man, Rogosa, and Sharpe (MRS) agar (Oxoid, Milan, Italy) supplemented with cycloheximide $\left(100 \mathrm{mg} / \mathrm{L}\right.$, Sigma-Aldrich, Gallarate, Italy), at $37^{\circ} \mathrm{C}$ for $48 \mathrm{~h}$ under anaerobiosis (Anaerogen Gas Pack, Oxoid); lactococci grew on M17 agar (Oxoid) at $37^{\circ} \mathrm{C}$ for $48 \mathrm{~h}$.

\section{Sensorial Analysis}

Sensory evaluation was carried out according to IDF (1995) standards and Juric et al. (2003). A panel composed of 6 members of the food packaging laboratory was assembled. The panelists were selected based on their interest in the sensory evaluation of cheese and trained by testing commercial spreadable cheese. 
Cheese samples (15 to $20 \mathrm{~g}$ ) with and without chitosan were submitted in a group to the 6 panelists. They were asked to evaluate the external appearance, texture, flavor, and overall acceptability of the spreadable cheese samples on a 5 -point scale $(1=$ not like very much; 5 = like very much; www.nutrition.org.uk/upload/Hedonic\%20Scale.pdf; Koca and Metin, 2004). Moreover, panelists were asked to list defects, if any were detected. The cheese samples were randomly coded.

\section{Statistical Analysis}

The results were compared by a one-way ANOVA. Duncan's multiple range test, with the option of homogeneous groups $(P<0.05)$ to determine significant differences between spreadable cheese samples, was used. Moreover, the interactions between sensorial firmness and the dynamic-mechanical properties of the Apulia spreadable cheese samples were evaluated by using multiple linear stepwise regression $(P<0.05)$; Statistica software, version 7.1 for Windows (StatSoft Inc., Tulsa, OK) was used for these purposes.

\section{RESULTS AND DISCUSSION}

As has been discussed, the effect of chitosan on the physicochemical, rheological, microbiological, and sensorial characteristics of Apulia spreadable cheese were addressed in this work. In the following section, the spreadable cheese properties are presented and discussed separately.

\section{Physicochemical Properties}

Changes in physicochemical attributes during the entire observation period of the 4 types of spreadable cheese investigated in this study are shown in Table 1. The initial $\mathrm{pH}$ values showed no difference in the spreadable cheese samples with and without chitosan, whereas significant differences in $\mathrm{pH}$ values among cheese samples were observed until the end of the storage period. In the control sample, the $\mathrm{pH}$ changed during the whole storage period but a trend was not observed. Similar results were also obtained for the spreadable cheese samples with the addition of chitosan. $\mathrm{pH}$ data of the control sample were similar to those reported by Alves et al. (2007) and Lee et al. (2004). pH is an ultimate indicator of an optimum cheese-making process, because acidity influences flavor, prevents pathogen growth, and controls enzyme activity and mineral balance (Corradini, 1995). The data listed in Table 1 also suggest that the addition of chitosan to cheese influenced its physicochemical properties.

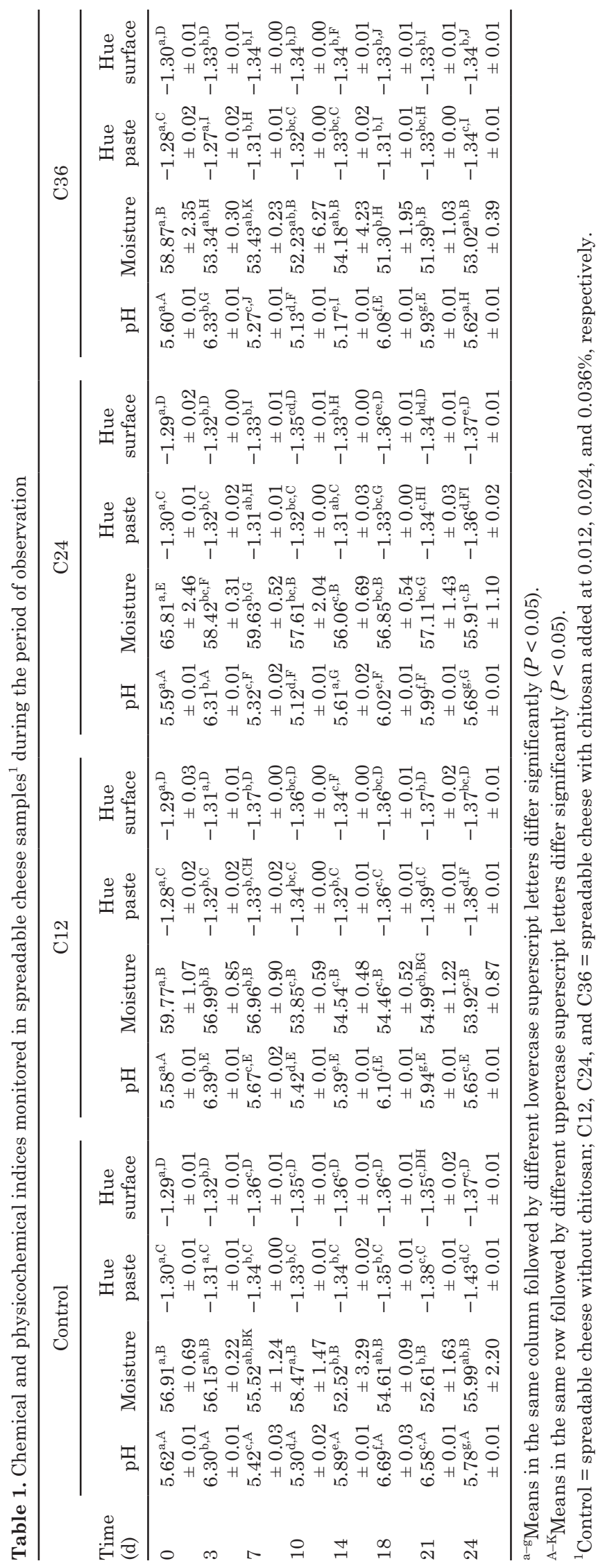

Journal of Dairy Science Vol. 91 No. 11, 2008 


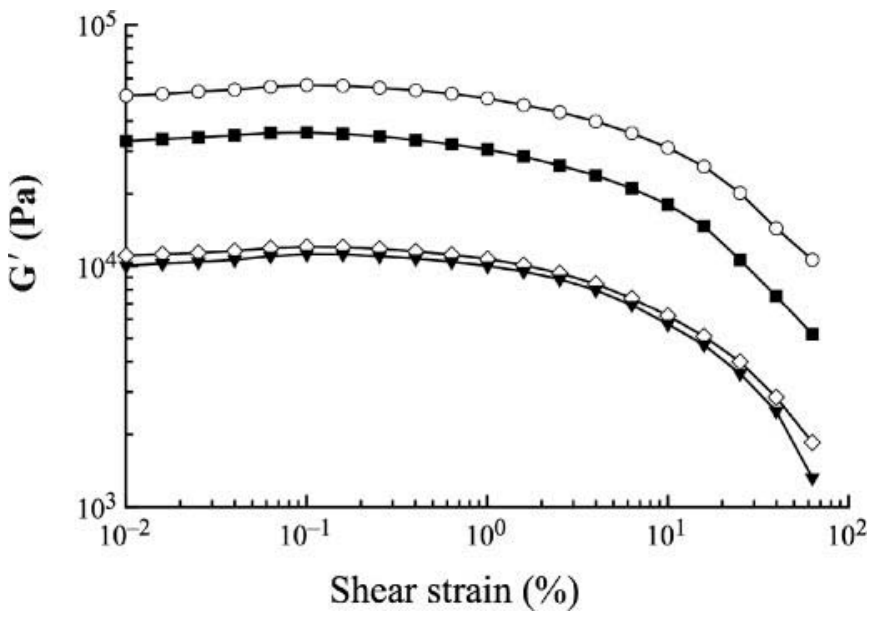

Figure 1. Storage modulus $\left(\mathrm{G}^{\prime}\right)$ values as function of shear strain for the (⿶) control, ( $(\circ) \mathrm{C} 12,(\diamond) \mathrm{C} 24$, and $(\boldsymbol{\nabla}) \mathrm{C} 36$ samples at d 14 . Control $=$ spreadable cheese without chitosan; $\mathrm{C} 12, \mathrm{C} 24$, and $\mathrm{C} 36=$ spreadable cheese with chitosan added at $0.012,0.024$, and $0.036 \%$, respectively.

Statistically significant differences of hue values in the spreadable cheese paste were recorded during storage (Table 1). Minor changes in hue values of the cheese surface were recorded during the entire period. Moreover, the hue values of cheese samples with the addition of chitosan were lower or showed no difference to the corresponding hue value of the control sample.

The moisture contents are reported in Table 1 . The C12 and C24 spreadable cheese samples showed a significant decrease in moisture values during the storage time. For instance, the C24 moisture value varied between $65.81 \%$ at $\mathrm{d} 0$ and $55.91 \%$ at $\mathrm{d} 24$. On the other hand, the control and C36 cheese samples showed a slight decrease in moisture during storage. Moreover, there were significant variations between some investigated cheese samples at d $0,3,7,18$, and 21 , whereas at the other storage times, the cheese samples with and without chitosan showed a similar moisture content.

\section{Rheological Analysis}

To determine the limit of the linear viscoelastic region for the investigated spreadable cheeses, a preliminary strain sweep oscillatory test was carried out. An example of the strain sweep oscillatory curve for the control, C12, C24, and C36 samples at d 14 is shown in Figure 1. It can be observed that the critical strain of all cheese samples is about 3\%. For all other storage times the cheese samples showed a similar trend (data not shown).

Figure 2 reports the $\mathrm{G}^{\prime}$ and $\mathrm{G}^{\prime \prime}$ values vs. the oscillatory frequency of the 2 spreadable cheese samples (control and $\mathrm{C} 24$ ) at d 14. A similar trend for the $\mathrm{G}^{\prime}$

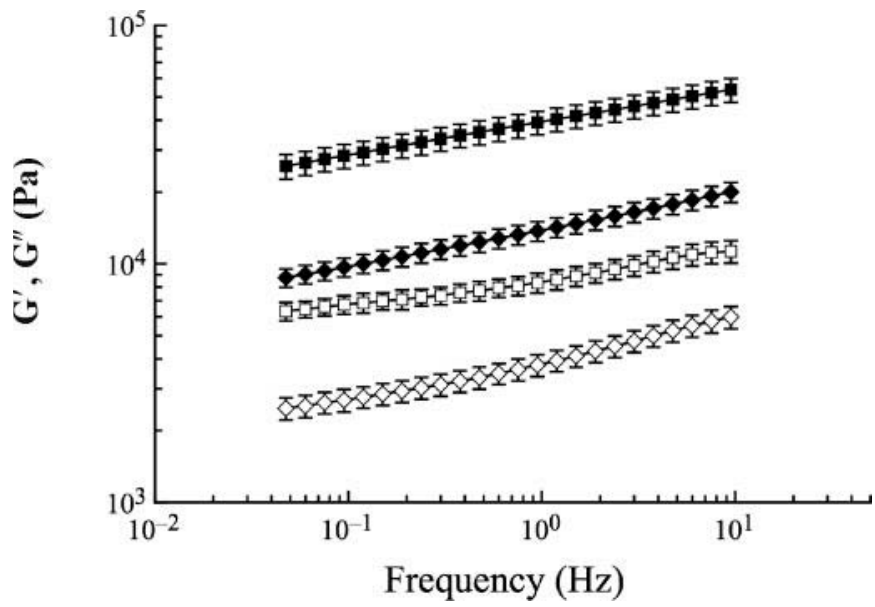

Figure 2. Storage modulus ( $\mathrm{G}^{\prime}$, closed symbols) and loss modulus $\left(\mathrm{G}^{\prime \prime}\right.$, open symbols) values as function of oscillatory frequency at d 14 storage time for the spreadable cheese samples: control ( $\square$ and $\square$ ) and $\mathrm{C} 24(\diamond$ and $\diamond)$. Control $=$ spreadable cheese without chitosan; $\mathrm{C} 24=$ spreadable cheese with chitosan added at $0.024 \%$.

and $\mathrm{G}^{\prime \prime}$ values was noted for the $\mathrm{C} 12$ and $\mathrm{C} 36$ cheese samples and for all other storage times, with the exception of the d 0 time. In fact, at $d 0$, all spreadable cheese samples had $\mathrm{G}^{\prime}$ and $\mathrm{G}^{\prime \prime}$ values statistically equal in the frequency range investigated in this study (data not shown). As can be seen in this figure, both $G^{\prime}$ and $\mathrm{G}^{\prime \prime}$ values of all cheese samples were dependent on frequency, indicating a viscoelastic behavior of the investigated food matrix. Moreover, the trends of $\mathrm{G}^{\prime}$ and $G^{\prime \prime}$ for the examined spreadable cheese samples were similar. It can be inferred from Figure 2 that the $G^{\prime}$ values for all cheese samples are larger than the $G^{\prime \prime}$ values. This is typical of a viscoelastic solid (Rao and Steffe, 1992), which presents a dominant contribution of the elastic component to the viscoelasticity (Subramanian and Gunasekaran, 1997). The spreadable cheese samples, shown in Figure 2, had a solid-like gel behavior with rheological spectra resembling that of weak gel (Ross-Murphy, 1988; Richardson et al., 1989). Typical weak gel characteristics were observed: $G^{\prime}$ was greater than $\mathrm{G}^{\prime \prime}$ throughout the frequency range, and the moduli showed a slight dependence on frequency. Similar behavior was observed in processed cheese spreads (Lee and Klostermeyer, 2001). The $G^{\prime}$ and $\mathrm{G}^{\prime \prime}$ values of control were similar to those of the C12 sample, whereas the $\mathrm{C} 24$ and C36 samples had similar $\mathrm{G}^{\prime}$ and $\mathrm{G}^{\prime \prime}$ values. The $\mathrm{G}^{\prime}$ and $\mathrm{G}^{\prime \prime}$ values of the control and $\mathrm{C} 12$ spreadable cheese samples were significantly greater compared with those of C24 and C36. Thus, the storage and loss moduli decreased with the increase in the chitosan concentration. In consequence, chitosan determined a decrease both in the storage and loss modulus, improving the softness of the cheese. This is 

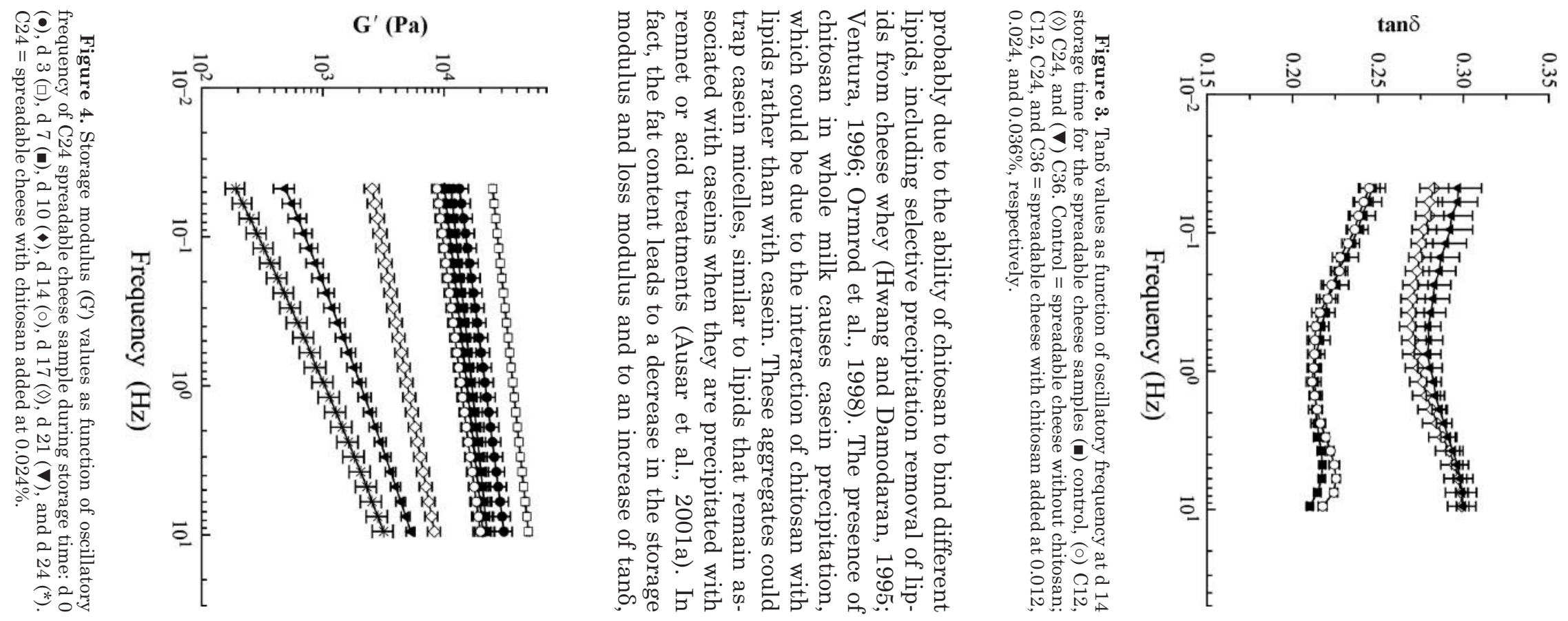

Table 2. Storage modulus $\left(\mathrm{G}^{\prime}\right)$,

\begin{tabular}{|c|c|c|c|c|c|c|c|c|c|c|c|c|}
\hline & $\mathrm{G}^{\prime}(\mathrm{Pa})$ & $\mathrm{G}^{\prime \prime}(\mathrm{Pa})$ & $\tan \delta$ & $\mathrm{G}^{\prime}(\mathrm{Pa})$ & $\mathrm{G}^{\prime \prime}(\mathrm{Pa})$ & $\tan \delta$ & $\mathrm{G}^{\prime}(\mathrm{Pa})$ & $\mathrm{G}^{\prime \prime}(\mathrm{Pa})$ & $\tan \delta$ & $\mathrm{G}^{\prime}(\mathrm{Pa})$ & $\mathrm{G}^{\prime \prime}(\mathrm{Pa})$ & $\tan \delta$ \\
\hline Control & $\begin{array}{r}109,907.56^{\mathrm{a}, \mathrm{A}} \\
\pm 18,347.12\end{array}$ & $\begin{array}{r}21,891.27^{\mathrm{a}, \mathrm{B}} \\
\pm 3,486.64\end{array}$ & $\begin{array}{l}0.19^{\mathrm{a}, \mathrm{C}} \\
\pm 0.001\end{array}$ & $\begin{array}{c}66,067.11^{\mathrm{a}, \mathrm{D}} \\
\pm 2.453 .611\end{array}$ & $\begin{array}{c}12,184.44^{\mathrm{a}, \mathrm{E}} \\
\quad \pm 741.05\end{array}$ & & $\begin{array}{l}53,718.06^{\mathrm{a}, \mathrm{F}} \\
\quad \pm 6,144.64\end{array}$ & $\begin{array}{r}11,280.55^{\mathrm{a}, \mathrm{E}} \\
\pm 1,209.83\end{array}$ & $\begin{array}{l}0.21^{\mathrm{a}, \mathrm{G}} \\
\pm 0.001\end{array}$ & $\begin{array}{c}24,169.79^{\mathrm{a}, \mathrm{H}} \\
\pm 992.42\end{array}$ & $\begin{array}{c}8,690.38^{\mathrm{a}, \mathrm{I}} \\
\pm 501.43\end{array}$ & $\begin{array}{l}0.36^{\mathrm{a}, J} \\
\pm 0.006\end{array}$ \\
\hline $\mathrm{C} 12$ & $\begin{array}{r}111,124.24^{\mathrm{a}, \mathrm{A}} \\
\quad \pm 18,725.67\end{array}$ & $\begin{array}{r}21,235.13^{\mathrm{a}, \mathrm{B}} \\
+324066\end{array}$ & $0.19^{\mathrm{a}, \mathrm{C}}$ & $\begin{array}{r}103,318.20^{\mathrm{b}, \mathrm{A}} \\
+15.631 .50\end{array}$ & $\begin{array}{r}21,611.13^{\mathrm{b}, \mathrm{B}} \\
+3.771 .94\end{array}$ & & $\begin{array}{c}99,196.83^{\mathrm{b}, \mathrm{A}} \\
+14.046 .26\end{array}$ & $\begin{array}{r}21,595.64^{\mathrm{b}, \mathrm{B}} \\
+3.19217\end{array}$ & $0.21^{\mathrm{a}, \mathrm{C}}$ & $22,580.54^{\mathrm{a}, \mathrm{D}}$ & $6,939.86^{\mathrm{b}, \mathrm{E}}$ & $0.31^{\mathrm{b}, \mathrm{F}}$ \\
\hline $\mathrm{C} 24$ & $\begin{array}{r}104,436.01^{\mathrm{a}, \mathrm{A}} \\
+19.317 .46\end{array}$ & $\begin{array}{r}19,847.37^{\mathrm{a}, \mathrm{B}} \\
+3.46987\end{array}$ & $\begin{array}{l}0.19^{\mathrm{a}, \mathrm{C}} \\
\pm 0.002\end{array}$ & $\begin{array}{r}22,657.27^{\mathrm{c}, \mathrm{D}} \\
+3.624 .57\end{array}$ & $\begin{array}{c}5,173.97^{\mathrm{c}, \mathrm{E}} \\
+625.30\end{array}$ & $\begin{array}{l}0.23^{\mathrm{c}, \mathrm{F}} \\
\pm 0.009\end{array}$ & $20,015.15^{c, D}$ & $5,987.68^{\mathrm{c}, \mathrm{E}}$ & $0.29^{\mathrm{b}, \mathrm{G}}$ & $5,768.26^{\mathrm{b}, \mathrm{H}}$ & $3,741.44^{\mathrm{c}, \mathrm{I}}$ & $0.65^{\mathrm{b}, \mathrm{J}}$ \\
\hline C36 & $\begin{array}{r}104,210.14^{\mathrm{a}, \mathrm{A}} \\
\pm 19,680.45\end{array}$ & $\begin{array}{r} \pm 3,4690^{\mathrm{a}, \mathrm{B}} \\
19,817.99 \mathrm{a}^{2} \\
\pm 3,933.42\end{array}$ & $\begin{array}{l} \pm 0.002 \\
0.19^{\mathrm{a}, \mathrm{C}} \\
\pm 0.003\end{array}$ & $\begin{array}{r} \pm 3,624.57 \\
33,215.40^{\mathrm{c}, \mathrm{D}} \\
\pm 4,971.28\end{array}$ & $\begin{array}{c} \pm 625.30 \\
7,728.74^{\mathrm{c}, \mathrm{E}} \\
\pm 1,171.69\end{array}$ & $\begin{array}{l} \pm 0.009 \\
0.23^{\mathrm{c}, \mathrm{F}} \\
\pm 0.001\end{array}$ & $\begin{array}{c} \pm 1,953.46 \\
12,504.68^{\mathrm{c}, \mathrm{G}} \\
\pm 971.13\end{array}$ & $\begin{array}{c} \pm 638.18 \\
3,749.10^{\mathrm{c}, \mathrm{H}} \\
\pm 337.10\end{array}$ & $\begin{array}{l} \pm 0.008 \\
0.29^{b, I} \\
\pm 0.003\end{array}$ & $\begin{array}{r} \pm 622.02 \\
1,636.35^{\mathrm{c}, \mathrm{J}} \\
\pm 483.46\end{array}$ & $\begin{array}{c} \pm 461.15 \\
1,389.09^{\mathrm{d}, \mathrm{K}} \\
\pm 347.58\end{array}$ & $\begin{array}{c} \pm 0.06 \\
0.85^{c, \mathrm{~L}} \\
\pm 0.02\end{array}$ \\
\hline
\end{tabular}

${ }^{a-d}$ Means in the same column followed by different lowercase superscript letters differ significantly $(P<0.05)$.

${ }^{\mathrm{A}-\mathrm{L}} \mathrm{Means}$ in the same row followed by different uppercase superscript letters differ significantly $(P<0.05)$.

${ }^{1}$ Control $=$ spreadable cheese without chitosan; $\mathrm{C} 12, \mathrm{C} 24$, and C36 = spreadable cheese with chitosan added at $0.012,0.024$, and $0.036 \%$, respectively 
resulting in a more liquid-like behavior of the cheese. This is due to the presence of fat, which acts as a lubricant. Similar results were found by Subramanian et al. (2006) who showed that fat reduction leads to an increase of viscoelasticity in processed cheese.

Figure 3 shows the $\tan \delta$ values vs. the oscillatory frequency of the 4 spreadable cheese samples (control, $\mathrm{C} 12$, C24, and C36) at d 14. As can be inferred from the figure, the $\tan \delta$ values for the control and $\mathrm{C} 12$ samples and for the C24 and C36 samples were similar. Moreover, the tan $\delta$ values were greater for the C24 and C36 samples with respect to the control and $\mathrm{C} 12$ samples. All cheese samples had similar tan $\delta$ values up to $d 10$ storage time, whereas from d 14 onward, the spreadable cheese samples had similar behavior to that shown at d 14. These results show that the greater the chitosan concentrations are, the more the cheese flows.

Figure 4 reports the $\mathrm{G}^{\prime}$ values of the C24 sample as a function of the oscillatory frequency at different storage times. In this figure, it can be observed that $\mathrm{G}^{\prime}$ at d $0,3,7,14$, and 17 storage times is slightly increased with the increase of frequency. On the other hand, at d 21 and 24, there was an important increase of $G^{\prime}$ as a function of the frequency. The other cheese samples showed a similar behavior during storage time. As can be observed at $d 7,10$, and 14 storage times, the $\mathrm{G}^{\prime}$ values of the C24 sample were similar. Subsequently, there was a significant increase of the storage modulus values as a function of frequency until the end of storage.

With the aim of better understanding the influence of chitosan on the rheological properties of spreadable cheese samples during storage, the $\mathrm{G}^{\prime}, \mathrm{G}^{\prime \prime}$, and $\tan \delta$ values at the oscillatory frequency of $10 \mathrm{~Hz}$ were compared. Table 2 reports the $\mathrm{G}^{\prime}, \mathrm{G}^{\prime}$, and $\tan \delta$ values of all spreadable cheese samples at $10 \mathrm{~Hz}$ frequency and at 4 different storage times (d 0, 7, 14, and 21). It can be observed in the table that the control, C24, and C36 cheese samples showed a significant decrease in $G^{\prime}$ and $G^{\prime \prime}$ values during storage time. For the $\mathrm{C} 12$ cheese sample, the $G^{\prime}$ and $G^{\prime \prime}$ values were constant for up to d 14 storage time. Afterward, this sample showed a significant decrease of the $\mathrm{G}^{\prime}$ and $\mathrm{G}^{\prime \prime}$ values until the end of storage. Moreover, at $d 0$, the 4 cheese samples showed close values of $\mathrm{G}^{\prime}, \mathrm{G}^{\prime \prime}$, and $\tan \delta$ values. The control and $\mathrm{C} 12$ samples had significantly greater $\mathrm{G}^{\prime}$ and $\mathrm{G}^{\prime \prime}$ values with respect to the C24 and C36 samples at other storage times. The latter 2 samples had statistically equal values of $\mathrm{G}^{\prime}$ and $\mathrm{G}^{\prime \prime}$ up to $\mathrm{d} 14$. In contrast, the C36 sample showed significantly lower $\mathrm{G}^{\prime}$ and $\mathrm{G}^{\prime \prime}$ values compared with those of $\mathrm{C} 24$ at $d 21$. As can be inferred from the table, the tan $\delta$ values increased during storage and with the increase of chitosan concentration, showing a predominant viscous behavior of

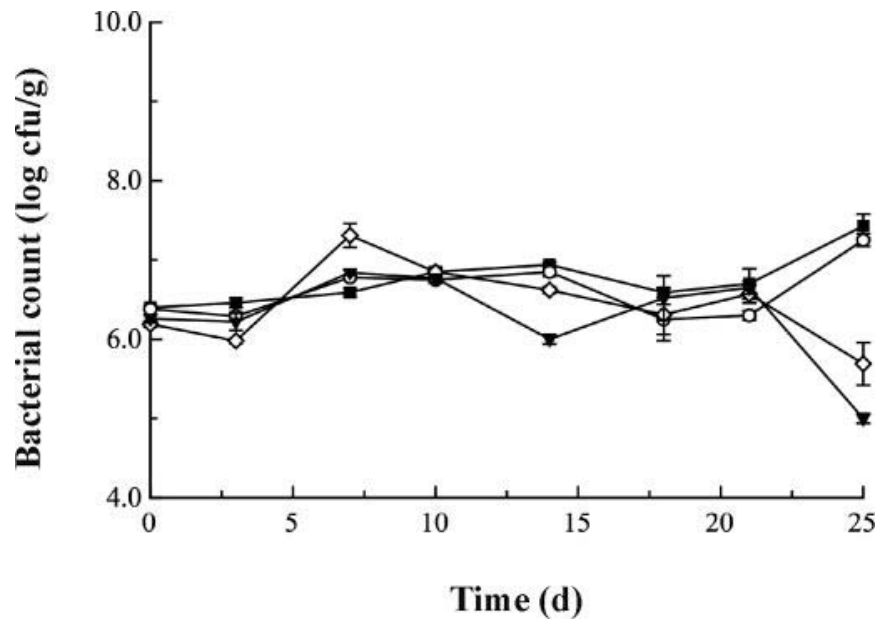

Figure 5. Evolution of lactic acid bacteria bacilli count in spreadable cheese samples during storage at $4^{\circ} \mathrm{C}$ : (®) control, ( $(\circ) \mathrm{C} 12,(\diamond)$ $\mathrm{C} 24$, and $(\boldsymbol{\nabla}) \mathrm{C} 36$. Control = spreadable cheese without chitosan; $\mathrm{C} 12, \mathrm{C} 24$, and $\mathrm{C} 36=$ spreadable cheese with chitosan added at 0.012 , 0.024 , and $0.036 \%$, respectively.

the spreadable cheese. Overall, the spreadable cheese samples with the greater concentrations of chitosan were softer and more spreadable. Some factors can influence the viscoelastic properties of the cheese such as water content, proteolysis, and pH (Juan et al., 2004). According to Luyten (1988), decreasing water content causes a decrease of $\tan \delta$, whereas proteolysis leads to an increase of this value. On the other hand, Visser (1991) found that an increase in $\mathrm{pH}$ of Gouda cheese resulted in a decrease in $\tan \delta$.

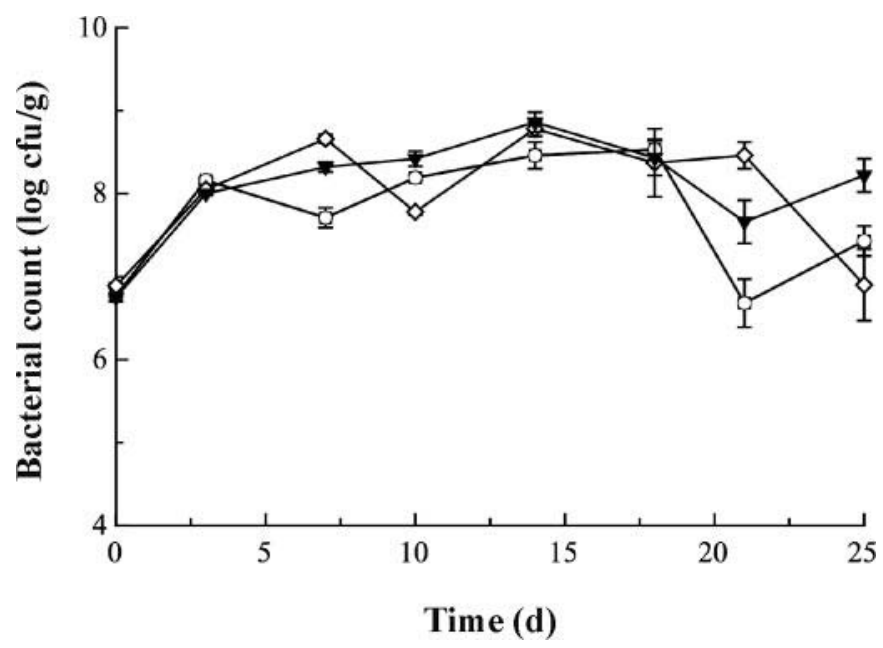

Figure 6. Evolution of lactic acid bacteria cocci count in spread-

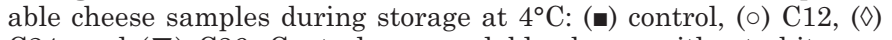
$\mathrm{C} 24$, and $(\boldsymbol{\nabla}) \mathrm{C} 36$. Control = spreadable cheese without chitosan; $\mathrm{C} 12, \mathrm{C} 24$, and $\mathrm{C} 36=$ spreadable cheese with chitosan added at 0.012 , 0.024 , and $0.036 \%$, respectively. 
Table 3. The appearance, texture, flavor, overall acceptability, and sensorial acceptability limit (SAL) values of spreadable cheese samples

\begin{tabular}{lccccc}
\hline Cheese sample $^{1}$ & Appearance & Texture & Flavor & Overall acceptability & SAL \\
\hline Control & $13.5841 \pm 1.7930$ & $1.6970 \pm 0.3201$ & $12.0642 \pm 1.4785$ & $10.5630 \pm 0.6483$ & $1.6970^{\mathrm{a}} \pm 0.3201$ \\
C12 & $8.5467 \pm 0.8802$ & $3.6404 \pm 1.2514$ & $9.8137 \pm 1.6395$ & $8.1048 \pm 0.5181$ & $3.6404^{\mathrm{b}} \pm 1.2514$ \\
C24 & $>18$ & $10.1804 \pm 1.2918$ & $>18$ & $>18$ & $10.1804^{\mathrm{c}} \pm 1.2918$ \\
C36 & $7.3339 \pm 0.8132$ & $4.4595 \pm 1.3208$ & $7.6308 \pm 0.8552$ & $3.7101 \pm 0.8644$ & $3.7101^{\mathrm{b}} \pm 0.8644$ \\
\hline
\end{tabular}

${ }^{\mathrm{a}-\mathrm{c}}$ Means in the same column followed by different superscript letters differ significantly $(P<0.05)$.

${ }^{1}$ Control $=$ spreadable cheese without chitosan; $\mathrm{C} 12, \mathrm{C} 24$, and $\mathrm{C} 36=$ spreadable cheese with chitosan added at $0.012,0.024$, and $0.036 \%$, respectively.

\section{Microbiological Analysis}

All cheese samples were submitted to microbiological analysis to assess the presence of lactic acid bacteria during the storage period. It is interesting to note that the lactic acid bacteria (Figures 5 and 6) were slightly stimulated by chitosan, suggesting the potential use of chitosan as a natural fiber for the development of new fermented dairy products. Ouattara et al. (2000) and Altieri et al. (2005) proved that chitosan had little effect on the lactic acid bacteria.

\section{Sensorial Analysis}

As reported above, the sensory quality of the investigated spreadable cheese was monitored both during ripening $(7 \mathrm{~d})$ and refrigerated storage $(18 \mathrm{~d})$. In particular, cheese appearance, texture, flavor, and overall

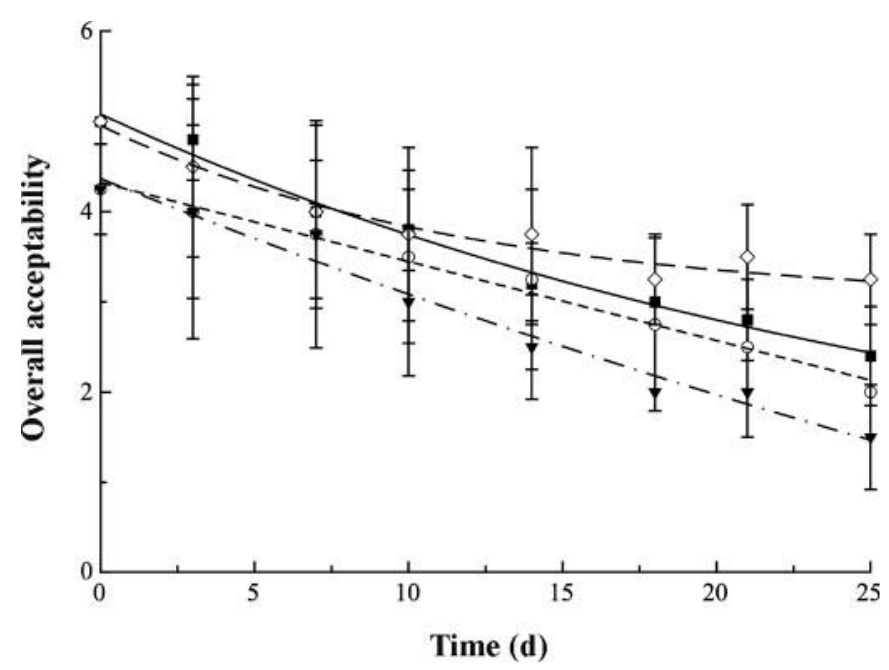

Figure 7. The overall acceptability plotted as a function of storage time for the control spreadable cheese sample, ( $\mathbf{c}$ ) experimental data and (-) best fit; for the C12 spreadable cheese sample, ( $\circ$ ) experimental data and (----) best fit; for the C24 spreadable cheese sample, $(\diamond)$ experimental data and $(----)$ best fit; for the C36 spreadable cheese sample, $(\boldsymbol{\nabla})$ experimental data and $(-\cdot-)$ best fit. Control $=$ spreadable cheese without chitosan; $\mathrm{C} 12, \mathrm{C} 24$, and C36 $=$ spreadable cheese with chitosan added at $0.012,0.024$, and $0.036 \%$, respectively. acceptability were assessed by 6 trained panelists. To quantitatively determine the influence of chitosan on the sensorial quality decay of Apulia spreadable cheese during storage, a first-order kinetic type equation was fitted to the experimental data:

$$
\begin{aligned}
& S A(t)=\frac{S A_{\min }-S A_{0} \cdot \exp (-k \cdot S A L)}{1-\exp (-k \cdot S A L)} \\
& +\left(S A_{0}-\frac{S A_{\min }-S A_{0} \cdot \exp (-k \cdot S A L)}{1-\exp (-k \cdot S A L)}\right) \cdot \exp (-k \cdot t)
\end{aligned}
$$

where $S A(t)$ is the investigated Apulia spreadable cheese sensorial attribute at time $t ; k$ is kinetic constant; $S A_{0}$ is the initial value of the Apulia spreadable cheese sensorial attribute; $S A_{\min }$ is the spreadable cheese sensorial attribute threshold limit; $S A L$ is the sensorial acceptability limit (i.e., the time at which $S A(t)$ is equal to $S A_{\text {min }}$ ); and $t$ is the storage time.

As an example, Figure 7 shows the overall acceptability of Apulia spreadable cheese plotted as a function of storage time for control and for the cheese samples with the addition of chitosan. The curves shown in Figure 7 were obtained by fitting equation [1] to the experimental data. The results are listed in Table 3. As can be seen in the figure, equation [1] satisfactorily fits the experimental data. Data listed in Table 3 show that appearance, texture, flavor, and overall acceptability of the investigated cheese are affected by the addition of chitosan. The sensorial acceptability limit (SAL) of the investigated cheese is also reported in Table 3. As can be inferred from data listed in the table, product unacceptability is generally related to the texture of the investigated spreadable cheese. Moreover, the data reported in Table 3 also highlight that the spreadable cheese samples with the addition of chitosan had SAL values greater than the control sample. In particular, the C12 and C36 samples showed a similar SAL, which is about $50 \%$ higher than that of the control sample. On the other hand, the C24 sample showed a much greater SAL than the C12 and C36 samples, which is about 5 
Table 4. Multiple linear stepwise regression to evaluate the interactions between the sensorial texture and rheological properties of the spreadable cheese samples (control, C12, C24, and C36) ${ }^{1,2}$

\begin{tabular}{|c|c|c|c|c|}
\hline Variable $^{3}$ & $\begin{array}{l}\text { Coefficient of } \\
\text { regression (B) }\end{array}$ & $\mathrm{SE}$ & Student $t$-test & $P$-level \\
\hline $\mathrm{G}_{\mathrm{CON}}^{\prime}$ & 0.000026 & 0.000007 & 3.682412 & 0.010301 \\
\hline $\mathrm{G}^{\prime \prime} \mathrm{CON}^{2}$ & - & - & - & - \\
\hline $\tan \delta_{\mathrm{CON}}$ & 5.571821 & 1.500932 & 3.712242 & 0.009943 \\
\hline $\mathrm{G}^{\prime} \mathrm{C} 12$ & 0.000017 & 0.000006 & 2.693564 & 0.035882 \\
\hline $\mathrm{G}^{\prime \prime}{ }_{\mathrm{C} 12}{ }^{2}$ & - & - & - & - \\
\hline $\tan \delta_{\mathrm{C} 12}$ & 6.641816 & 2.013609 & 3.298564 & 0.016439 \\
\hline $\mathrm{G}_{\mathrm{C} 24}^{\prime}{ }^{2}$ & - & - & - & - \\
\hline $\mathrm{G}^{\prime \prime}{ }_{24}$ & 0.000466 & 0.000068 & 6.826065 & 0.000485 \\
\hline $\tan \delta_{\mathrm{C} 24}$ & 2.043815 & 0.980461 & 2.084545 & 0.082216 \\
\hline $\mathrm{G}_{\mathrm{C} 36}^{\prime}{ }^{2}$ & - & - & - & - \\
\hline $\mathrm{G}^{\prime \prime}{ }_{\mathrm{C} 36}$ & 0.000451 & 0.000043 & 10.54343 & 0.000043 \\
\hline $\tan \delta_{\mathrm{C} 36}$ & 1.291558 & 0.474956 & 2.71932 & 0.034674 \\
\hline
\end{tabular}

times that of the control sample. Results suggest that chitosan strongly influences the texture decay of the investigated spreadable cheese during storage.

Table 4 reports the results of the multiple linear stepwise regression to evaluate the interaction between sensorial texture and rheological properties of the spreadable cheese samples. In this table the accuracy coefficient of the model was also reported (Ross, 1996). It can also be observed that the sensorial texture showed a positive regression coefficient for the $\mathrm{G}^{\prime}$ and $\tan \delta$ values of the control and $\mathrm{C} 12$ samples. Moreover, it can be inferred that, for the C24 and C36 samples, the sensorial texture is positively correlated to the $\mathrm{G}^{\prime \prime}$ and $\tan \delta$ values, thus corroborating the idea that chitosan does affect the spreadability of the investigated cheese.

\section{CONCLUSIONS}

Results obtained in this study suggest that the addition of chitosan to Apulia spreadable cheese had a positive effect on its rheological properties. In particular, an increase of the chitosan concentration determined a decrease of $G^{\prime}, G^{\prime \prime}$, and an increase of $\tan \delta$. This variation of the rheological characteristics brought an improvement in the softness and spreadability of the investigated cheese. The cheese SAL also increased with the addition of chitosan. In fact, the C24 sample showed a SAL 5 times that of the control cheese. Moreover, the chitosan influenced the physicochemical properties without affecting the dairy microflora.

\section{ACKNOWLEDGMENTS}

This research work, which falls into the Strategic Project "Miglioramento della qualità dietetico-nutriz- ionale e sicurezza di produzioni casearie tradizionali della Capitanata," was financially supported by the Apulia Region. The authors gratefully acknowledge R. De Feudis and "Caseificio Posta la via" for providing the spreadable cheese samples used in the experiment.

\section{REFERENCES}

Altieri, C., C. Scrocco, M. Sinigaglia, and M. A. Del Nobile. 2005. Use of chitosan to prolong Mozzarella cheese shelf life. J. Dairy Sci. 88:2683-2688

Alves, R. M. V., A. G. F. Van Denderb, S. B. M. Jaimea, I. Morenob, and B. C. Pereiraa. 2007. Effect of light and packages on stability of spreadable processed cheese. Int. Dairy J. 17:365-373.

APHA. 2001. Compendium of Methods for the Microbiological Examination of Foods. 5th ed. P. D. Frances and I. Keith, ed. American Public Health Association, Washington, DC.

Ausar, S. F., I. D. Bianco, R. G. Badini, L. F. Castagna, N. M. Modesti, C. A. Landa, and D. M. Beltramo. 2001a. Characterization of casein micelle precipitation by chitosans. J. Dairy Sci. 84:361369.

Ausar, S. F., C. A. Landa, I. D. Bianco, L. F. Castagna, and D. M. Beltramo. 2001b. Hydrolysis of chitosan-induced milk aggregates by pepsin, trypsin and pancreatic lipase. Biosci. Biotechnol. Biochem. 65:2412-2418.

Ausar, S. F., N. Passalacqua, L. F. Castagna, I. D. Bianco, and D. M. Beltramo. 2002. Growth of milk fermentative bacteria in the presence of chitosan for potential use in cheese making. Int. Dairy J. 12:899-906.

Berger, W., H. Klostermeyer, K. Merkenich, and G. Uhlmann. 1993. Pages 91-92 in Processed Cheese Manufacture. H. Klostermeyer, ed. Würzburg Universitätsdruckerei BK, Ladenburg $\mathrm{GmbH}$, Germany.

Corradini, C. 1995. I componenti minerali. Pages 63-67 in Chimica e Tecnologia del Latte. C. Corradini, ed. Tecniche Nuove, Milan, Italy.

Dickinson, E. 1998. Stability and rheological implications of electrostatic milk protein-polysaccharide interactions. Trends Food Sci. Technol. 9:347-354.

Dimitreli, G., and A. S. Thomareis. 2008. Effect of chemical composition on the linear viscoelastic properties of spreadabletype processed cheese. J. Food Eng. 84:368-374.

Drake, M. A., T. D. Boylston, and B. G. Swanson. 1996. Fat mimetics in low-fat Cheddar cheese. J. Food Sci. 61:1267-1270. 
Hwang, D., and S. Damodaran. 1995. Selective precipitation and removal of lipids from cheese whey using chitosan. J. Agric. Food Chem. 43:33-37.

IDF. 1995. Guide for the Sensory Evaluation of Cheese. Standard 99A, part IV. International Dairy Federation, Brussels, Belgium.

Juan, B., V. Ferragut, B. Guamis, M. Buffa, and A. J. Trujillo. 2004. Proteolysis of high pressure-treated ewe's milk cheese. Milchwissenschaft 59:616-619.

Juric, M., G. Bertelsen, G. Montensen, and M. A. Petersen. 2003. Light-induced colour and aroma changes in sliced, modified atmosphere packaged semi-hard cheeses. Int. Dairy J. 13:239249

Koca, N., and M. Metin. 2004. Textural, melting and sensory properties of low-fat fresh kasher. Int. Dairy J. 14:365-373.

Konuklar, G., G. E. Ingletta, K. Warnerb, and C. J. Carriere. 2004. Use of a B-glucan hydrocolloidal suspension in the manufacture of low-fat Cheddar cheeses: Textural properties by instrumental methods and sensory panels. Food Hydrocolloids 18:535-545.

Lante, A., G. Lomolino, M. Cagnin, and P. Spettoli. 2006. Content and characterisation of minerals in milk and in Crescenza and Squacquerone Italian fresh cheeses by ICP-OES. Food Contr. 17:229-233.

Lee, S. K., S. Anema, and H. Klostermeyer. 2004. The influence of moisture content on the rheological properties of processed cheese spread. Int. J. Food Sci. Technol. 39:763-771.

Lee, S. K., and H. Klostermeyer. 2001. The effect of $\mathrm{pH}$ on the rheological properties of reduced-fat model processed cheese spreads. Lebensm. Wiss. Technol. 34:288-292.

Li, Q., E. T. Dunn, E. W. Grandmaison, and M. F. A. Goosen. 1997. Application and properties of chitosan. Pages 3-30 in Application of Chitin and Chitosan. M. F. A. Goosen, ed. Technomic Publishing, Lancaster, UK.

Luyten, H. 1988. The rheological and fracture properties of Gouda cheese. PhD Thesis. Wageningen Agricultural Univ., Wageningen, the Netherlands.

Ma, L., M. A. Drake, G. V. Barbosa-Cánovas, and B. G. Swanson. 1997. Rheology of full-fat and low-fat Cheddar cheeses as related to type of fat mimetic. J. Food Sci. 62:748-752.

McMahon, D. J., M. C. Alleyne, R. L. Fife, and C. J. Oberg. 1996. Use of fat replacers in low fat Mozzarella cheese. J. Dairy Sci. 79:1911-1921.

No, H. K., S. P. Meyers, W. Prinyawiwatkul, and Z. Xu. 2007. Applications of chitosan for improvement of quality and shelf life of foods: A review. J. Food Sci. 72:87-100.

Ormrod, D. J., C. C. Holmes, and T. E. Miller. 1998. Dietary chitosan inhibits hypercholesterolaemia and atherogenesis in the apolipoprotein E-deficient mouse model of atherosclerosis. Atherosclerosis 138:329-334

Ouattar, B., R. E. Simard, G. Piette, A. Bègin, and R. A. Holley. 2000. Inhibition of surface spoilage bacteria in processed meats by application of antimicrobial films prepared with chitosan. Int. J. Food Microbiol. 62:139-148.

Piska, I., and J. Štětina. 2004. Influence of cheese ripening and rate of cooling of the processed cheese mixture on rheological properties of processed cheese. J. Food Eng. 61:551-555.
Rao, M. A., and J. F. Steffe. 1992. Viscoelastic Properties of Foods. Elsevier Applied Science, New York, NY

Richardson, R. K., E. R. Morris, S. B. Ross-Murphy, L. J. Taylor, and I. C. M. Dea. 1989. Characterisation of the perceived texture of the thickened systems by dynamic viscosity measurements. Food Hydrocolloids 3:175-191.

Romeih, E. A., A. Michaelidou, C. G. Biliaderis, and G. K. Zerfiridis, 2002. Low-fat white-brined cheese made from bovine milk and two commercial fat mimetics: Chemical, physical and sensory attributes. Int. Dairy J. 12:525-540.

Ross, T. 1996. Indices for performance evaluation of predictive models in food microbiology. J. Appl. Bacteriol. 81:501-508.

Ross-Murphy, S. B. 1988. Small deformation measurements. Pages 387-400 in Food Structure: Its Creation and Evaluation. J. M. V. Blanshard, and J. R. Mitchell, ed. Butterworths, London, UK.

San Martín-González, M.F., J. J Rodríguez, S. Gurrama, S. Clark, B. G. Swanson, and G. V. Barbosa-Cánovas. 2007. Yield, composition and rheological characteristics of cheddar cheese made with high pressure processed milk. Lebensm. Wiss. Technol. 40:697-705.

Sekiguchi, S., Y. Miura, H. Kaneko, S. I. Nishimura, N. Nishi, M. Iwase, and S. Tokura. 1994. Molecular weight dependency of antimicrobial activity by chitosan oligomers. Pages 71-76 in Food Hydrocolloids: Structures, Properties and Functions. K. Nishinari and E. Doi., ed. Plenum, New York, NY.

Sipahioglu, O., V. B. Alvarez, and C. Solano-Lopez. 1999. Structure, physicochemical and sensory properties of Feta cheese made with Tapioca starch and lecithin as fat mimetics. Int. Dairy J. 9:783-789

Subramanian, R., and S. Gunasekaran. 1997. Small amplitude oscillatory shear studies on Mozzarella cheese. Part I. Region of linear viscoelasticity. J. Texture Stud. 28:633-642.

Subramanian, R., K. Muthukumarappan, and S. Gunasekaran. 2006. Linear viscoelastic properties of regular- and reduced-fat pasteurized process cheese during heating and cooling. Int. J. Food Prop. 9:377-393.

Sugano, M., K. Yoshida, M. Hashimoto, K. Enamoto, and S. Hirano. 1992. Hipocholesterolemic activity of partially hydrolyzed chitosan in rats. Pages 472-478 in Advances in Chitin and Chitosan. C. Y. Brine, P. A. Sandford, J. P. Zikakis, ed. Elsevier, London, UK.

Tokoro, A., N. Tatewaki, K. Suzuki, T. Mikami, S. Suzuki, and M. Suzuki. 1988. Growth-inhibitory effect of hexa-N acetylchitohexaose and chitohexaose against Meth-A solid tumor. Chem. Pharm. Bull. (Tokyo) 36:784-790.

Ventura, P. 1996. Lipid lowering activity of chitosan, a new dietary integrator. Pages 55-62 in Chitin Enzimology. Vol. 2. R. A. A. Muzarelli, ed. Atec Edizioni, Grottammare, Italy.

Visser, J. 1991. Factors affecting the rheological and fracture properties of hard and semi-hard cheese. Pages 49-61 in Vol. 268. International Dairy Federation, Brussels, Belgium.

Zalazar, C. A., C. S. Zalazar, S. Bernal, N. Bertola, A. Bevilacqua, and N. Zaritzky. 2002. Effect of moisture level and fat replacer on physicochemical, rheological and sensory properties of low fat soft cheeses. Int. Dairy J. 12:45-50. 